\title{
The Prognostic Impact of Estimated Creatinine Clearance by Bioelectrical Impedance Analysis in Heart Failure: Comparison of Different eGFR Formulas
}

\author{
Pietro Scicchitano $^{1, *\left(\mathbb{D}, \text { Massimo Iacoviello }^{2} \mathbb{D} \text {, Andrea Passantino }\right.}{ }^{3}$, Piero Guida ${ }^{4}$, Micaela De Palo ${ }^{5}$, \\ Assunta Piscopo ${ }^{1}$, Michele Gesualdo ${ }^{1}$, Pasquale Caldarola ${ }^{6}$ and Francesco Massari ${ }^{1}$ \\ 1 Cardiology Section, Hospital “F. Perinei”, 70022 Altamura, Italy; assuntapiscopo@alice.it (A.P.); \\ michelegesualdo@libero.it (M.G.); franco_massari@libero.it (F.M.) \\ 2 Cardiology Unit, Department of Medical and Surgical Science, University of Foggia, 71122 Foggia, Italy; \\ massimo.iacoviello@gmail.com \\ 3 Division of Cardiology and Cardiac Rehabilitation, Scientific Clinical Institutes Maugeri, IRCCS Institute of \\ Bari, 70124 Bari, Italy; andrea.passantino@icsmaugeri.it \\ 4 Regional General Hospital “F. Miulli”, 70021 Acquaviva delle Fonti, Italy; pieroguida@libero.it \\ 5 Cardiac Surgery Section, Policlinico University Hospital, 70124 Bari, Italy; micaela.depalo85@gmail.com \\ 6 Cardiology Section, Hospital “S. Paolo", 70123 Bari, Italy; pascald1506@gmail.com \\ * Correspondence: piero.sc@hotmail.it; Tel.: +39-080-310-8286
}

Citation: Scicchitano, P.; Iacoviello, M.; Passantino, A.; Guida, P.; De Palo, M.; Piscopo, A.; Gesualdo, M.; Caldarola, P.; Massari, F. The Prognostic Impact of Estimated Creatinine Clearance by Bioelectrical Impedance Analysis in Heart Failure: Comparison of Different eGFR Formulas. Biomedicines 2021, 9, 1307. https://doi.org/10.3390/biomedicines 9101307

Academic Editor: Bart De Geest

Received: 22 August 2021

Accepted: 20 September 2021

Published: 24 September 2021

Publisher's Note: MDPI stays neutral with regard to jurisdictional claims in published maps and institutional affiliations.

Copyright: (c) 2021 by the authors. Licensee MDPI, Basel, Switzerland. This article is an open access article distributed under the terms and conditions of the Creative Commons Attribution (CC BY) license (https:// creativecommons.org/licenses/by/ $4.0 /)$.

\begin{abstract}
The estimation of glomerular filtration rate (eGFR) provides prognostic information in patients with heart failure (HF). Bioelectrical impedance analysis may calculate eGFR (Donadio formula). The aim of this study was to evaluate the impact of the Donadio formula in predicting all-cause mortality in patients with HF as compared to Cockroft-Gault, MDRD-4 (Modification of Diet in renal Disease Study), and Chronic Kidney Disease Epidemiology Collaboration (CKD-EPI) formulas. Four-hundred thirty-six subjects with $\mathrm{HF}$ ( $52 \%$ men; mean age $75 \pm 11$ years; $42 \%$ acute HF) were enrolled. Ninety-two patients (21\%) died during the follow-up (median 463 days, IQR 287-669). The area under the receiver operator characteristic curve for eGFR, as estimated by Cockroft-Gault formula (AUC = 0.75), was significantly higher than those derived from Donadio (AUC = 0.72), MDRD-4 (AUC $=0.68)$, and CKD-EPI (AUC $=0.71)$ formulas. At multivariate analysis, all eGFR formulas were independent predictors of death; $1 \mathrm{~mL} / \mathrm{min} / 1.73 \mathrm{~m}^{2}$ increase in eGFR-as measured by Cockroft-Gault, Donadio, MDRD-4, and CKD-EPI formulas-provided a 2.6\%, 1.5\%, 1.2\%, and $1.6 \%$ increase, respectively, in mortality rate. Conclusions. eGFR, as calculated with the Donadio formula, was an independent predictor of mortality in patients with HF as well as the measurements derived from MDRD4 and CKD-EPI formulas, but less accurate than Cockroft-Gault.
\end{abstract}

Keywords: acute heart failure; chronic heart failure; BIA; BNP; clearance creatinine; prognosis

\section{Introduction}

The assessment of glomerular filtration rate (GFR) is mandatory in the management of patients with heart failure (HF). About $23 \%$ of patients with HF show worsening renal function (WRF) as a consequence of the impairment in kidney perfusion, pharmacological treatments, and neuro-hormonal activation [1-3]. The literature has reported prevalence in WRF in acute decompensated HF patients ranging from $25 \%$ to $40 \%$ [4].

The worsening in kidney function in both acute (AHF) and chronic (CHF) patients is related to poor outcomes [1]. It is associated with a two-fold increase in all-cause mortality risk [1].

No matter the type of HF [5,6], WRF is related to a 2-3-fold increase in adverse in-hospital outcomes and 1.5-fold increase in 1-year mortality [5].

Therefore, the need for monitoring renal function is one of the mainstays in the general management of patients with both AHF and CHF. Several formulas and equations have 
been created to assess and monitor the performance of the kidneys during hospital stay for HF: Cockroft-Gault, Modification of Diet in Renal Disease Study (MDRD-4), and the Chronic Kidney Disease Epidemiology Collaboration (CKD-EPI) are the best representative formulas in this setting [7-9]. The literature has provided different results about the prognostic value of each formula in HF patients [10-14]. According to Zamora et al. [14], CG has the most accurate risk predictive skill compared to MDRD and CKD-EPI in HF patients. McAlister et al. [15] compared MDRD and CKD-EPI as predictors of mortality in HF patients, finding that CKD-EPI seemed more reliable than MDRD in predicting all-cause mortality at 3-year follow-up. Casado Cerrada et al. [16] demonstrated that CKD-EPI was able to better re-classify patients with AHF (net reclassification improvement [NRI]: 6.78\%).

Indeed, the influence of body weight, muscular mass, and creatinine production may limit the use of creatinine-based formulas. The application of bioimpedance analysis (BIA) to the estimation of glomerular filtration rate (eGFR) may provide further insights to clinicians $[17,18]$. Donadio et al. $[17,18]$ estimated GFR from body cell mass (BCM), as assessed by total body BIA. The value of BCM is strictly correlated with 24 urine creatinine excretion ( $\mathrm{UCr}$ ) [17]; therefore, it is possible to estimate GFR by combining BCM and plasma creatinine $[17,18]$.

The aims of this study were to evaluate the prognostic value of eGFR as assessed by the Donadio formula, and to compare it to Cockroft-Gault, MDRD-4, and CKD-EPI formulas in HF patients.

\section{Materials and Methods}

\subsection{Study Populations}

This was a retrospective study based on a cohort of patients who were consecutively admitted to the Cardiology Unit of "F. Perinei" Hospital in Altamura (Bari, Italy), due to AHF or CHF, between January 2016 and November 2019.

The dataset included the clinical/anthropometric characteristics of the study population, blood biochemical data, BIA measurements, and pharmacological treatments. The left ventricular ejection fraction (LVEF) was calculated with Simpson's method by means of echocardiography. BNP levels were assessed using a microparticle enzyme immunoassay (Architect, Abbott Park, IL, USA), while serum creatinine was measured with a Beckman Coulter AU 680 chemistry analyser (Beckman Coulter s.r.l. Via Roma, 108-Cassina Plaza 20060 - Cassina De' Pecchi Milan, Italy). All these measurements were routinely performed for all patients at admission to our ward.

Exclusion criteria consisted of myocarditis, pericarditis, pulmonary embolism, acute coronary syndrome, and recent cardiac surgery intervention.

The primary endpoint was all-cause death as ascertained from available medical records or National Death Records.

All patients gave their written informed consent to collect all the data related to their hospital stay. The performance of the study was in agreement with the Declaration of Helsinki. The study was approved by the local Institutional Review Board of the ASL BARI (protocol n. 0081801/CE—29 October 2015, study number: 4816).

\subsection{Creatinine-Based Formulas for Estimating GFR}

We calculated estimated GFR with the use of the following formulas: Donadio, Cockroft-Gault, MDRD-4, and CKD-EPI equations. GFR was expressed in $\mathrm{mL} / \mathrm{min} / 173 \mathrm{~m}^{2}$ :

(1) The Donadio formula was obtained by using tetrapolar impedance plethysmography, which emitted a single alternating sinusoidal current at $50 \mathrm{kHz}$ (CardioEFG, Akern RJL Systems, Florence, Italy). The values of resistance and reactance were measured, and $\mathrm{BCM}$ was calculated according to the manufacturer's equation. Urinary Creatinine Excretion (Ucr) estimation was obtained as follows: Ucr $(\mathrm{mg} / 24 \mathrm{~h})=\mathrm{BCM}(\mathrm{Kg}) \times$ $30.2+$ height $(\mathrm{cm}) \times$ age $($ years $) \times 8.35-2222$, while eGFR was calculated as: Ucr $(\mathrm{mg}) /$ plasma creatinine $(\mathrm{mg} / \mathrm{mL}) \times 1440 \mathrm{~min}[17,18]$; 
(2) The Cockroft-Gault formula: $(140-$ age $) \times($ weight $) /(72 \times$ serum creatinine $) \times 0.85$ (if female) [7];

(3) The MDRD-4 formula: $186.3 \times$ creatinine $-1.154 \times$ age $-0.203 \times 1.212$ (if black) $\times$ 0.742 (if female) [8];

(4) The CKD-EPI formula: male: $141 \times$ minimum (creatinine $/ 0.9,1)-0.411 \times$ maximum (creatinine $/ 0.9,1)-1.209 \times 0.993$ Age $\times 1.159$ (if black); female: $141 \times$ minimum (creatinine/0.7, 1) $-0.329 \times$ maximum (creatinine/0.7,1) $-1.209 \times 0.993$ Age $\times 1.018$ $\times 1.159$ (if black) [9].

\subsection{Statistical Analysis}

Normally distributed variables are reported as mean (standard deviation), and nonnormally distributed continuous variables as median [25th-75th interquartile range (IQR)].

Because the distribution of BNP levels had a skewed distribution, a logarithm was used to obtain an optimal residual analysis. The comparisons between survivor and non-survivor groups were performed with a Student's $t$-test or Mann-Whitney U-test where appropriate. Receiver-operating characteristic (ROC) curve analysis was performed to calculate the area under the curve (AUC) values, and the optimal cut-off values for mortality were calculated as the point of maximum sensitivity and specificity. The AUCs were compared using Hanley and McNeil tests. Survival was calculated using KaplanMeier analysis.

Univariate and multivariate analyses were performed to evaluate hazard ratios (HR) between eGFR formulas and all-cause mortality using Cox for proportional hazards. For multivariate analysis, we adjusted for variables considered to be of potential prognostic impact, such as ischemic heart disease, history of diabetes, atrial fibrillation, NYHA functional class, LVEF, serum sodium, BNP, hemoglobin, and HF status (AHF vs. CHF). After Pearson's test between blood urea nitrogen and eGFR formulas ( $r>0.60$ for all), blood urea nitrogen dropped from multivariate Cox analysis because it was redundant. $p$-values below 0.05 were defined as statistically significant. The analyses were performed using STATA software, version 12 (StataCorp, College Station, TX, USA).

\section{Results}

There were 436 patients included in this study. Table 1 gathers the main characteristics of the patients.

The BCM was $24 \pm 8 \mathrm{Kg}$, estimated Ucr was $1068 \pm 381 \mathrm{mg}$ and mean eGFR as derived from Donadio formula was $64 \pm 35 \mathrm{~mL} / \mathrm{min} / 1.73 \mathrm{~m}^{2}$. The Cockroft-Gault, MDRD-4, and CKD-EPI formulas revealed the following mean eGFR values: $58 \pm 27 \mathrm{~mL} / \mathrm{min} / 1.73 \mathrm{~m}^{2}$, $53 \pm 27 \mathrm{~mL} / \mathrm{min} / 1.73 \mathrm{~m}^{2}$, and $53 \pm 28 \mathrm{~mL} / \mathrm{min} / 1.73 \mathrm{~m}^{2}$, respectively.

In relation to the different formulas, the prevalence of renal insufficiency-as defined by eGFR $<60 \mathrm{~mL} / \mathrm{min} / 1.73 \mathrm{~m}^{2}$ — was $53 \%$ with the Donadio formula, $57 \%$ with CockroftGault formula, 69\% with MDRD-4 formula, and 68\% with CKD-EPI formula.

Ninety-two (21\%) patients died during the follow-up (median 463 days, IQR 287-669). Patients with AHF showed a significantly higher mortality rate (31\%) than those with CHF $(13 \%)(p<0.0001)$. ROC curves analysis tried to evaluate the role of eGFR formulas in predicting all-cause mortality risk and the optimal cut-off points to be considered for the best prediction (Table 2).

As reported in Figure 1, the ROC curve related to Cockroft-Gault formula was significantly higher than those derived from the other formulas.

The long-term survival Kaplan-Meier curves of the four formulas-categorized according to the different stages of kidney failure-are shown in Figure 2. 
Table 1. Patient characteristics.

\begin{tabular}{|c|c|}
\hline Clinical Characteristics & $n=436$ \\
\hline Age, yrs & $75 \pm 11$ \\
\hline Male, \% & 52 \\
\hline BMI, $\mathrm{kg} / \mathrm{m}^{2}$ & $28 \pm 5$ \\
\hline NYHA I-II/III/IV, \% & $43 / 30 / 27$ \\
\hline Peripheral oedema, \% & 30 \\
\hline Medical history, \% & \\
\hline Coronary artery disease & 30 \\
\hline Diabetes & 24 \\
\hline Atrial fibrillation & 43 \\
\hline $\mathrm{PM} / \mathrm{ICD}$ & 18 \\
\hline AHF & 42 \\
\hline LVEF, \% & $43 \pm 12$ \\
\hline Preserved LVEF, \% & 48 \\
\hline Mid-range LVEF, \% & 10 \\
\hline Reduced LVEF, \% & 42 \\
\hline \multicolumn{2}{|l|}{ Laboratory values } \\
\hline $\mathrm{BNP}, \mathrm{pg} / \mathrm{dL}$ & $510(199-1100)$ \\
\hline Hemoglobin, g/dL & $13 \pm 2$ \\
\hline Uric acid, $\mathrm{mg} / \mathrm{dL}$ & $6.2 \pm 2.1$ \\
\hline BUN, mg/dL & $30 \pm 17$ \\
\hline Creatinine, $\mathrm{mg} / \mathrm{dL}$ & $1.4 \pm 0.9$ \\
\hline Sodium, mmol/L & $139 \pm 4$ \\
\hline Potassium, $\mathrm{mmol} / \mathrm{L}$ & $4.0 \pm 0.6$ \\
\hline Chloride, mmol/L & $103 \pm 5$ \\
\hline Albumin, g/dL & $3.3 \pm 0.6$ \\
\hline \multicolumn{2}{|l|}{ Bioelectrical Impedance Parameters } \\
\hline Resistance/height, $\mathrm{Ohm} / \mathrm{m}$ & $309 \pm 68$ \\
\hline Reactance/height, Ohm/m & $27 \pm 8$ \\
\hline \multicolumn{2}{|l|}{ Therapies, \% } \\
\hline Furosemide & 69 \\
\hline Beta-blockers & 50 \\
\hline ACE inhibitors/ARBs & 60 \\
\hline MRAs & 69 \\
\hline Digitalis & 21 \\
\hline Ivabradine & 5 \\
\hline
\end{tabular}

Numbers are expressed as percentage or mean \pm standard deviation. Abbreviations: ACE: angiotensin-converting enzyme; AHF: acute heart failure; ARB: angiotensin receptor blocker; BMI: body mass index; BNP: brain natriuretic peptide; BUN: blood urea nitrogen; ICD: implanted cardioverter/defibrillator; LVEF: left ventricular ejection fraction; MRAs mineralocorticoid receptor antagonists; NYHA: New York Heart Association; PM: pacemaker.

Table 2. Performance of eGFR equations in predicting all-cause mortality.

\begin{tabular}{|c|c|c|c|c|c|c|c|c|c|}
\hline $\begin{array}{c}\text { eGFR } \\
\left(\mathrm{mL} / \mathrm{min} / 1.73 \mathrm{~m}^{2}\right)\end{array}$ & $\begin{array}{c}\text { Non- } \\
\text { Survivors } \\
(n=72)\end{array}$ & $\begin{array}{l}\text { Survivors } \\
(n=344)\end{array}$ & AUC (95\% CI) & Cut-Off & Sensitivity & Specificity & PPV & NPV & $p$ \\
\hline Donadio & $45 \pm 28$ & $70 \pm 35$ & $0.72(0.67-0.76)$ & $<51$ & 67 & 69 & 37 & 89 & $<0.0001$ \\
\hline Cockroft-Gault & $45 \pm 20$ & $61 \pm 28$ & $0.75(0.71-0.79)$ & $<50$ & 82 & 57 & 33 & 92 & $<0.0001$ \\
\hline MDRD-4 & $36 \pm 20$ & $58 \pm 28$ & $0.68(0.64-0.73)$ & $<43$ & 54 & 76 & 38 & 86 & $<0.0001$ \\
\hline CKD-EPI & $38 \pm 23$ & $58 \pm 29$ & $0.71(0.66-0.75)$ & $<41$ & 66 & 72 & 39 & 89 & $<0.0001$ \\
\hline
\end{tabular}

Abbreviations. AUC: area under the curve; CI: confidence interval; CKD-EPI: Chronic Kidney Disease Epidemiology Collaboration; eGFR: estimated glomerular filtration rate; MDRD-4: Modification of Diet in Renal Disease Study; NPV: negative predictive value; PPV: positive predictive value. 


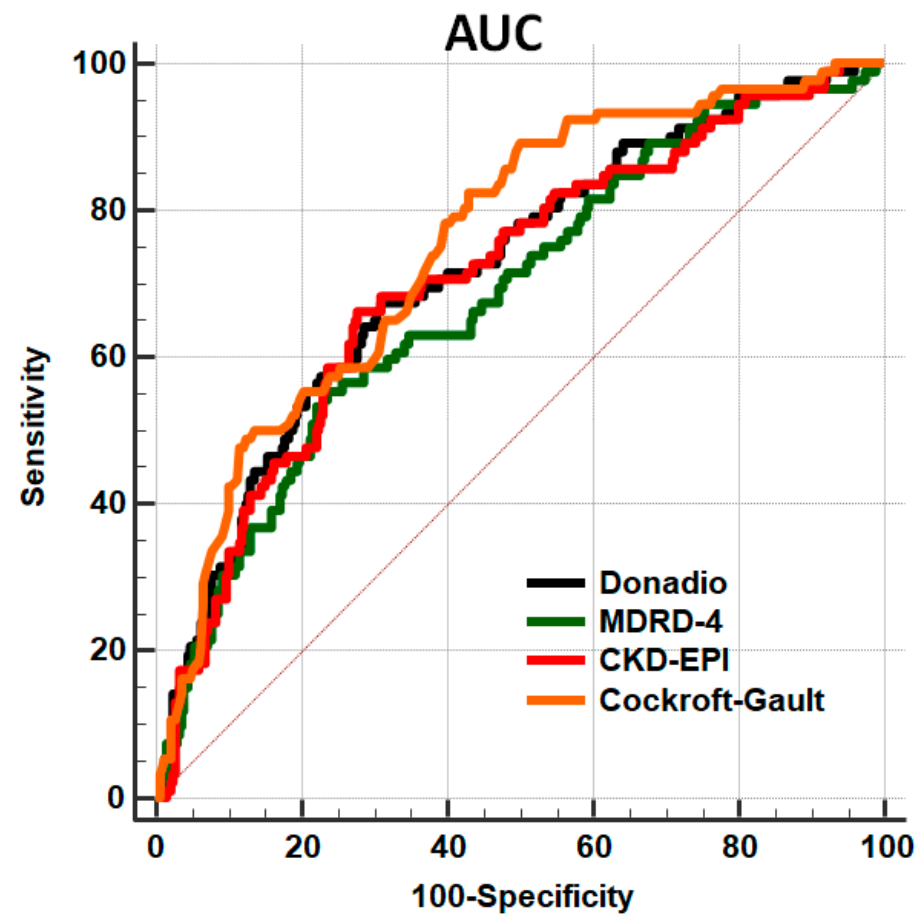

Figure 1. Area under the receiver operating characteristic curves (AUC) of the different eGFR formulas in predicting all-cause mortality. AUC derived from Cockroft-Gault formula was significantly higher than those from other formulas ( $p<0.05$ for all). Abbreviations: AUC: area under the curve; CKD-EPI: Chronic Kidney Disease Epidemiology Collaboration; MDRD-4: Modification of Diet in Renal Disease Study.
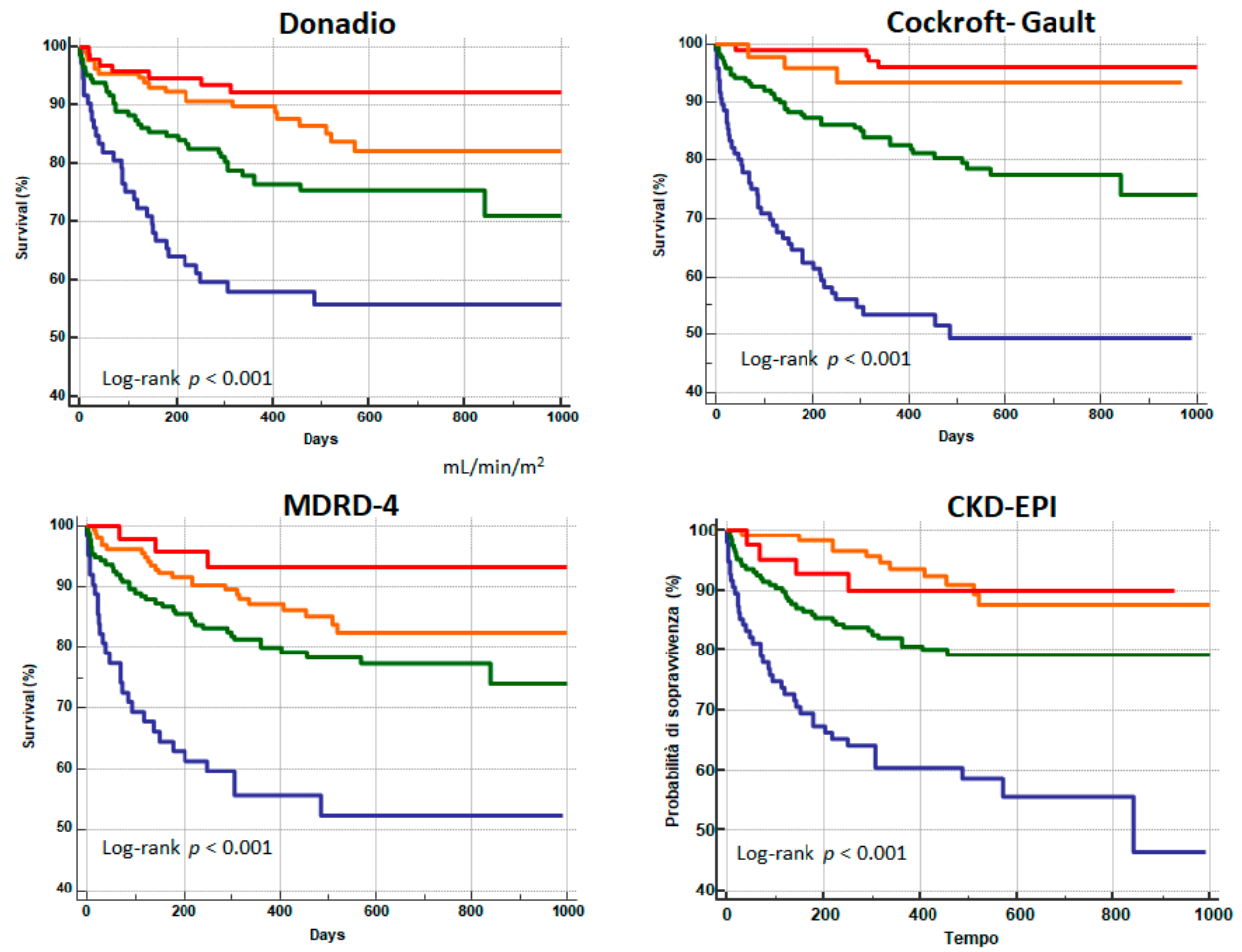

Figure 2. Kaplan-Meier survival curves relate to each formula for estimating glomerular filtration rate (GFR) at different stages of renal function: GFR: $<30 \mathrm{~mL} / \mathrm{min} / 1.73 \mathrm{~m}^{2}$ (red); GFR between 30 and $59 \mathrm{~mL} / \mathrm{min} / 1.73 \mathrm{~m}^{2}$ (orange); GFR between 60 and $90 \mathrm{~mL} / \mathrm{min} / 1.73 \mathrm{~m}^{2}$ (green); and GFR $>90 \mathrm{~mL} / \mathrm{min} / 1.73 \mathrm{~m}^{2}$ (blue). Abbreviations: CKD-EPI: Chronic Kidney Disease Epidemiology Collaboration; MDRD-4: Modification of Diet in Renal Disease Study. 
All the formulas are confirmed to be independent predictors of mortality in patients with HF. However, the curve from the Cockroft-Gault formula was more divergent than the others: chi-squared was 82 for Cockroft-Gault, 39 for Donadio, 39 for MDRD4, and 45 for CKD-EPI.

At univariate Cox proportional hazard analysis, all the eGFR formulas were predictors of death. After adjustment for HF covariates, all eGFR formulas confirmed to act as independent predictors of death. Specifically, each $1 \mathrm{~mL} / \mathrm{min} / 1.73 \mathrm{~m}^{2}$ point decrease in eGFR values as calculated by Cockroft-Gault, Donadio, MDRD4, and CKD-EPI formulas increased all-cause mortality risk by $2.6 \%, 1.5 \%, 1.2 \%$, and $1.6 \%$, respectively (Tables 3 and 4 ).

Table 3. Univariate Cox proportional hazards survival analyses.

\begin{tabular}{ccc}
\hline & \multicolumn{2}{c}{ Univariate Cox Regression Analysis } \\
\hline & HR (95\% CI) & $p$ \\
\hline Donadio & $0.976(0.968-0.983)$ & $<0.0001$ \\
Cockroft-Gault & $0.962(0.952-0.972)$ & $<0.0001$ \\
MDRD-4 & $0.976(0.967-0.984)$ & $<0.0001$ \\
CKD-EPI & $0.972(0.963-0.981)$ & $<0.0001$ \\
Coronary artery disease & $0.962(0.610-1.501)$ & $\mathrm{ns}$ \\
Diabetes & $1.081(0.681-1.722)$ & $\mathrm{ns}$ \\
Atrial fibrillation & $1.422(0.941-2.15)$ & $\mathrm{ns}$ \\
AHF vs. CHF & $2.721(1.782-4.12)$ & $<0.0001$ \\
NYHA I-II/III/IV & $1.823(1.45-2.38)$ & $\mathrm{ns}$ \\
LVEF, \% & $0.981(0.971-1.102)$ & $<0.0001$ \\
BNP, pg/dL $\times 100$ & $1.040(1.030-1.051)$ & $<0.0001$ \\
Hemoglobin, g/dL & $0.777(0.701-0.854)$ & $\mathrm{ns}$ \\
Sodium, mmol/L & $0.925(0.945-10.67)$ &
\end{tabular}

Abbreviations. AHF: acute heart failure; BNP: brain natriuretic peptide; CHF: chronic heart failure; CI: confidence interval; CKD-EPI: Chronic Kidney Disease Epidemiology Collaboration; eGFR: estimated glomerular filtration rate; HR: hazard ratio; LVEF: left ventricle ejection fraction; MDRD-4: Modification of Diet in Renal Disease Study; ns $=$ not significant; NYHA: New York Heart Association.

Table 4. Multivariate Cox proportional hazards survival analyses.

\begin{tabular}{cccc}
\hline & \multicolumn{2}{c}{ Adjusted Cox Regression Analysis } \\
\hline & HR (95\% CI) & $p$ & Wald \\
\hline Donadio & $0.985(0.977-0.994)$ & $=0.001$ & 6.5 \\
BNP, pg/dL $\times 100$ & $1.03(1.02-1.05)$ & $=0.001$ & 15.4 \\
& & & \\
Cockroft-Gault & $0.974(0.962-0.985)$ & $<0.001$ & 17.3 \\
BNP, pg/dL $\times 100$ & $1.02(1.01-10.4)$ & $=0.002$ & 9.4 \\
NYHA I-II/III/IV & $1.363(1.020-1.816)$ & $=0.036$ & 4.4 \\
MDRD-4 & $0.988(0.979-0.998)$ & $=0.03$ & 4.7 \\
BNP, pg/dL $\times 100$ & $1.030(1.020-1.040)$ & $=0.0002$ & 13.8 \\
NYHA I-II/III/IV & $1.336(1.001-1.783)$ & $<0.04$ & 4.9 \\
Hemoglobin, g/dL & $0.886(0.796-0.987)$ & $=0.03$ & 9.4 \\
CKDEPI & $0.984(0.974-0.994)$ & $=0.003$ & 12.7 \\
BNP, pg/dL $\times 100$ & $1.03(1.010-1.040)$ & $=0.0004$ & 17.3 \\
NYHA I-II/III/IV & $1.337(1.001-1.785)$ & $=0.04$ & \\
\hline
\end{tabular}

Abbreviations. BNP: brain natriuretic peptide; CI: confidence interval; CKD-EPI: Chronic Kidney Disease Epidemiology Collaboration; HR: hazard ratio; MDRD-4: Modification of Diet in Renal Disease Study; NYHA: New York Heart Association. 


\section{Discussion}

The prognostic value of eGFR in patients with HF represents a practical approach to the risk stratification of these patients by adopting findings from common biochemical data. Our study mainly demonstrated that four formulas-namely Donadio formula, CG, MDRD-4, and CKD-EPI-were able to assess the risk of all-cause mortality in HF patients. Specifically, our findings demonstrated that $C G$ formula provided the best prognostic value in HF compared to the other three formulas by revealing an AUC value of 0.75 for a cut-off value $<50 \mathrm{~mL} / \mathrm{min} / 1.73 \mathrm{~m}^{2}$, with sensitivity equal to $82 \%$, specificity $57 \%$, PPV $33 \%$, and NPV $92 \%$.

This is the first study trying to evaluate the prognostic role of the Donadio formula in patients with HF. The major innovative characteristic of our research was to provide a comprehensive tool, bioimpedance analysis, able to evaluate the congestion status of patients with HF, the occurrence of cardio-renal syndrome by providing information about GFR calculation, and the stratification of their mortality risk. Such results may provide a useful bedside approach to the clinical practice in early identification of subjects with HF and in cases with a poor prognosis.

The poor performance of MDRD-4 in predicting adverse events in HF patients was already established in the literature [19], although better results were demonstrated in postcardiac transplantation recipients [20] or patients with diabetes [21]. CKD-EPI provided better risk stratification than MDRD-4 in patients with HF after acute decompensation, although the AUC of the ROC curve did not overcome 0.64 in a study by Casado Cerrada et al. [16]. Further studies revealed the better prognostic value of CKD-EPI as compared to MDRD when evaluating the impact of GFR on the overall survival rate of patients with HF [15,22-24]. Indeed, the use of cystatin in CKD-EPI calculation provided a reason for the better performance of this equation in the setting of HF patients [25-30]. Our study pointed out that an CKD-EPI equation based on serum creatinine alone was able to predict all-cause mortality in patients with HF (AUC: 0.71); this prognostic value was maintained after multivariate Cox regression analysis.

The CG formula was the best formula for stratifying the risk of death in HF patients as compared to MDRD and CKD-EPI [14,31-33]. The AUC of GFR, as estimated by CG, was higher than 0.80 in a cohort of 925 HF outpatients, thus better discriminating the risk for death compared to GFR calculated by means of MDRD-4 and/or CKD-EPI [14]. Beyond patients with CHF [32], the CG formula was able to predict mortality better than MDRD and CKD-EPI also in patients with acute decompensation of HF [33]. We demonstrated the better performance of CG compared to the other formulas in both acute and chronic HF.

The most striking information related to our study was the demonstration of the good performance of the Donadio formula in predicting adverse events in HF patients. This is the first study dealing with the prognostic value of the Donadio formula in the setting of HF. The Donadio formula succeeded in combining bioimpedance analysis with the estimation of GFR, as previously demonstrated $[17,18]$. We also demonstrated that bioimpedance analysis may provide useful insights in HF patients: the evaluation of congestion by means of BIA and the association with further biomarkers may guide therapy, provide prognostic data, and predict length of stay [34-38]. The Donadio formula seemed to combine two fundamental aspects of HF pathogenesis: the evaluation of residual congestion/nutrition and the calculation of GFR, i.e., the assessment of cardio-renal syndrome. Indeed, there are no data about the prognostic value of eGFR as calculated by the Donadio formula in the setting of HF. We obtained an AUC of 0.72 with a cut-off $<51 \mathrm{~mL} / \mathrm{min} / 1.73 \mathrm{~m}^{2}$, the sensitivity and specificity set at $67 \%$ and $69 \%$, respectively, while NPV was $89 \%$. The Donadio equation was confirmed to act as an independent mortality risk factor in HF patients at multivariate Cox regression analysis, the Wald index being equal to 10.6.

These results are interesting. The formula created by Donadio et al. $[17,18]$ allowed us to overcome some limitations related to creatinine-based equations. Donadio et al. [39] also observed amelioration in GFR measurements in mildly obese individuals. Nevertheless, 
further studies are needed to better address the daily application of the Donadio formula, and the contextual evaluation of congestion by means of BIA in patients with HF.

\section{Limitations}

The retrospective nature of this study may be considered as a limitation. Indeed, we collected data from a large population of patients with $\mathrm{CHF}$ or AHF, who were followed-up by cardiologists committed to daily management of HF.

The use of BIA in daily clinical practice is not widespread, and this issue may represent a possible limitation. Nevertheless, the subtle aim of this study was also the promotion of this specific technique: the simple, fast, costless application of bioimpedance analysis. The great amount of clinical and prognostic information derived from it may induce clinicians to adopt this technique for a comprehensive evaluation of patients with HF and, along with the Donadio formula, cardio-renal syndrome.

The eGFR formulas had been all adjusted for body surface area (BSA). The literature provides concerns about this adjustment in clinical practice, as it may alter the correct estimation of eGFR, for example, in obese individuals [40,41]. Nevertheless, we adjusted all the formulas for BSA in order to make the results uniform to the aim of the study, which was to evaluate their prognostic impact in HF patients.

Equations may also underestimate eGFR in obese patients, above all when considering patients with severe forms of obesity (BMI $\left.>35 \mathrm{Kg} / \mathrm{m}^{2}\right)$ [42,43]. Indeed, no patient in our cohort showed very high BMI values, although the overall elevated BMI of the general population (mean value $28 \pm 5 \mathrm{Kg} / \mathrm{m}^{2}$ ) might effectively impact on eGFR calculations. Although the Donadio equation seemed to perform well in mildly obese individuals [39], the role of obesity in GFR calculation remains challenging. Further studies are needed in order to overcome this bias.

The lack of information about proteinuria and albuminuria is a further matter of debate for this research, above all in relation to the percentage of the enrolled diabetic patients (24\%). The impact of these parameters on cardio-renal syndrome has been previously established [44]. Albuminuria had been widely demonstrated to act as prognostic determinant in diabetic patients. The evaluation of albuminuria and proteinuria would add specific value to the multiparametric approach to HF patients for the comprehensive risk stratification of this category of patients.

The recent guidelines of the European Society of Cardiology on the management of HF [45] outlined the great positive influence of new antidiabetics in the prognosis of patients with HF. This study was performed before the introduction of glifozins in clinical practice. The confounding role of glifozins in the overall assessment of the prognosis of patients with HF would be an interesting starting point for further research.

A further limitation derives from the single center experience. Attempts to include further centers are ongoing, in the interest of demonstrating the validity of the results on larger populations.

\section{Conclusions}

The CG formula was confirmed to be an independent predictor of all-cause mortality in patients with AHF and CHF. The CG formula was superior to MDRD-4, Donadio, and CKD-EPI in the overall assessment of the prognosis of patients with HF. In addition, the application of BIA in a real-life cohort of patients with HF confirmed its prognostic value. Beyond the evaluation of congestion, BIA allows for the calculation of GFR and the prediction of adverse events related to kidney dysfunction in HF patients.

Author Contributions: Conceptualization, P.S. and F.M.; methodology, P.S., F.M., M.I., P.G., A.P. (Andrea Passantino); validation, P.S., M.I., F.M., A.P. (Assunta Piscopo), P.G., M.D.P., M.G., A.P. (Andrea Passantino), and P.C.; formal analysis, P.S., M.I., F.M., A.P. (Andrea Passantino), P.G., M.D.P., M.G., A.P. (Assunta Piscopo), and P.C.; investigation, P.S., M.I., F.M., A.P. (Andrea Passantino), P.G., M.D.P., M.G., A.P. (Assunta Piscopo), and P.C.; resources, P.S., M.I., F.M., and P.C.; data curation, P.S. and F.M.; writing —original draft preparation, P.S., M.I., F.M., A.P. (Andrea Passantino), P.G., M.D.P., 
M.G., A.P. (Assunta Piscopo), and P.C.; writing-review and editing, P.S., M.I., F.M., A.P. (Andrea Passantino), P.G., M.D.P., M.G., A.P. (Assunta Piscopo), and P.C.; visualization, P.S., M.I., F.M., A.P. (Andrea Passantino), P.G., M.D.P., M.G., A.P. (Assunta Piscopo), and P.C.; supervision, P.S., M.D.P., and F.M.; project administration, P.S. and F.M.; funding acquisition, P.S. and F.M. All authors have read and agreed to the published version of the manuscript.

Funding: This research received no external funding.

Institutional Review Board Statement: The study was conducted according to the guidelines of the Declaration of Helsinki, and approved by the local Institutional Review Board of the ASL BARI (protocol n. 0081801/CE-29/10/2015, study number: 4816).

Informed Consent Statement: Informed consent was obtained from all subjects involved in the study.

Data Availability Statement: The data will be available on request by contacting the Corresponding Author.

Conflicts of Interest: The authors declare no conflict of interest.

\section{References}

1. Damman, K.; Valente, M.A.; Voors, A.A.; O'Connor, C.M.; van Veldhuisen, D.J.; Hillege, H.L. Renal impairment, worsening renal function, and outcome in patients with heart failure: An updated meta-analysis. Eur. Heart J. 2013, 35, 455-469. [CrossRef]

2. Mullens, W.; Damman, K.; Testani, J.M.; Martens, P.; Mueller, C.; Lassus, J.; Tang, W.W.; Skouri, H.; Verbrugge, F.H.; Orso, F.; et al. Evaluation of kidney function throughout the heart failure trajectory-A position statement from the Heart Failure Association of the European Society of Cardiology. Eur. J. Heart Fail. 2020, 22, 584-603. [CrossRef]

3. Grande, D.; Gioia, M.I.; Terlizzese, P.; Iacoviello, M. Heart failure and kidney disease. Adv. Exp. Med. Biol. 2018, 1067, $219-238$.

4. Bozkurt, B.; Kamat, I.S. Worsening renal function in acute decompensated heart failure: A bad sign, or maybe not? Trans. Am. Clin. Climatol. Assoc. 2019, 130, 41-50.

5. Kang, J.; Park, J.J.; Cho, Y.; Oh, I.; Park, H.; Lee, S.E.; Kim, M.; Cho, H.; Lee, H.; Choi, J.O.; et al. Predictors and prognostic value of worsening renal function during admission in HFpEF Versus HFrEF: Data from the KorAHF (Korean Acute Heart Failure) registry. J. Am. Heart Assoc. 2018, 7, e007910. [CrossRef] [PubMed]

6. Grigorian Shamagian, L.; Varela Román, A.; Pedreira Pérez, M.; Gómez Otero, I.; Virgós Lamela, A.; González-Juanatey, J.R. Renal failure is an independent predictor of mortality in hospitalized heart failure patients and is associated with a worse cardiovascular risk profile. Rev. Esp. Cardiol. 2006, 59, 99-108. [CrossRef]

7. Cockroft, D.W.; Gault, M.H. Prediction of creatinine clearance from serum creatinine. Nephron 1976, 16, 31-41. [CrossRef] [PubMed]

8. Levey, A.S.; Greene, T.; Kusek, J.W.; Beck, G.J. A simplified equation to predict glomerular filtration rate from serum creatinine. J. Am. Soc. Nephrol. 2000, 11, 155A.

9. Levey, A.S.; Stevens, L.A.; Schmid, C.H.; Zhang, Y.L.; Castro, A.F.; Feldman, H.I.; Kusek, J.W.; Eggers, P.; van Lente, F.; Greene, T.; et al. CKD-EPI (Chronic Kidney Disease Epidemiology Collaboration). A new equation to estimate glomerular filtration rate. Ann. Intern. Med. 2009, 150, 604-612. [CrossRef]

10. Libório, A.; Uchoa, R.; Neto, J.; Valdivia, J.; Daher, E.; Mejia, J. Assessing glomerular filtration rate in patients with severe heart failure: Comparison between creatinine-based formulas. Sao Paulo Med. J. 2012, 130, 289-293. [CrossRef] [PubMed]

11. Valente, M.A.; Hillege, H.L.; Navis, G.; Voors, A.A.; Dunselman, P.H.; Van Veldhuisen, D.J.; Damman, K. The Chronic Kidney Disease Epidemiology Collaboration equation outperforms the Modification of Diet in Renal Disease equation for estimating glomerular filtration rate in chronic systolic heart failure. Eur. J. Heart Fail. 2013, 16, 86-94. [CrossRef]

12. Delanaye, P.; Nellessen, E.; Grosch, S.; DePas, G.; Cavalier, E.; Defraigne, J.-O.; Chapelle, J.-P.; Krzesinski, J.-M.; Lancellotti, P. Creatinine-based formulae for the estimation of glomerular filtration rate in heart transplant recipients. Clin. Transplant. 2006, 20, 596-603. [CrossRef] [PubMed]

13. Smilde, T.D.; van Veldhuisen, D.J.; Navis, G.; Voors, A.A.; Hillege, H.L. Drawbacks and prognostic value of formulas esti-mating renal function in patients with chronic heart failure and systolic dysfunction. Circulation 2006, 114, 1572-1580. [CrossRef] [PubMed]

14. Zamora, E.; Lupón, J.; Vila, J.; Urrutia, A.; de Antonio, M.; Sanz, H.; Grau, M.; Ara, J.; Bayés-Genís, A. Estimated glomerular filtration rate and prognosis in heart failure: Value of the modification of diet in renal disease study-4, chronic kidney disease epidemiology collaboration, and cockroft-gault formulas. J. Am. Coll. Cardiol. 2012, 59, 1709-1715. [CrossRef] [PubMed]

15. McAlister, F.A.; Ezekowitz, J.; Tarantini, L.; Squire, I.; Komajda, M.; Bayes-Genis, A.; Gotsman, I.; Whalley, G.; Earle, N.; Poppe, K.K.; et al. Meta-analysis Global Group in Chronic Heart Failure (MAGGIC) Investigators. Renal dysfunction in pa-tients with heart failure with preserved versus reduced ejection fraction: Impact of the new Chronic Kidney Disease-Epidemiology Collaboration Group formula. Circ. Heart Fail. 2012, 5, 309-314. [CrossRef] 
16. Cerrada, J.C.; Carrasco-Sánchez, F.J.; Perez-Calvo, J.I.; Manzano, L.; Formiga, F.; Bodas, O.A.; Conde, A.; Quiros, R.; Bocanegra, C.P.; Montero-Pérez-Barquero, M.; et al. Prognostic value of glomerular filtration rate estimation equations in acute heart failure with preserved versus reduced ejection fraction. Int. J. Clin. Pract. 2015, 69, 829-839. [CrossRef] [PubMed]

17. Donadio, C. Body composition analysis allows the prediction of urinary creatinine excretion and of renal function in chronic kidney disease patients. Nutrients 2017, 9, 553. [CrossRef] [PubMed]

18. Donadio, C.; Lucchesi, A.; Tramonti, G.; Bianchi, C. Creatinine clearance can be predicted from plasma creatinine and body composition analysis by means of electrical bioimpedance. Ren. Fail. 1998, 20, 285-293. [CrossRef]

19. Gardner, R.S.; Chong, K.S.; O'Meara, E.; Jardine, A.; Ford, I.; McDonagh, T.A. Renal dysfunction, as measured by the modification of diet in renal disease equations, and outcome in patients with advanced heart failure. Eur. Heart J. 2007, 28, 3027-3033. [CrossRef]

20. Singh, T.P.; Givertz, M.M.; Gauvreau, K. Risk stratification for in-hospital mortality after heart transplantation using the modification of diet in renal disease and the chronic kidney disease epidemiology collaboration equations for estimated glomerular filtration rate. Transplantation 2014, 98, 1000-1006. [CrossRef]

21. Tancredi, M.; Rosengren, A.; Olsson, M.; Gudbjörnsdottir, S.; Svensson, A.-M.; Haraldsson, B.; Lind, M. The relationship between three eGFR formulas and hospitalization for heart failure in 54,486 individuals with type 2 diabetes. Diabetes/Metab. Res. Rev. 2016, 32, 730-735. [CrossRef]

22. Skali, H.; Uno, H.; Levey, A.S.; Inker, L.A.; Pfeffer, M.A.; Solomon, S.D. Prognostic assessment of estimated glomerular fil-tration rate by the new Chronic Kidney Disease Epidemiology Collaboration equation in comparison with the Modification of Diet in Renal Disease Study equation. Am. Heart J. 2011, 162, 548-554. [CrossRef]

23. Oh, J.; Kang, S.-M.; Hong, N.; Youn, J.-C.; Han, S.; Jeon, E.-S.; Cho, M.-C.; Kim, J.-J.; Yoo, B.-S.; Chae, S.C.; et al. KorHF Registry. The CKD-EPI is more accurate in clinical outcome prediction than MDRD equation in acute heart failure: Data from the Korean Heart Failure (KorHF) Registry. Int. J. Cardiol. 2013, 167, 1084-1087. [CrossRef] [PubMed]

24. Plischke, M.; Neuhold, S.; Kohl, M.; Heinze, G.; Pacher, R.; Hülsmann, M.; Sunder-Plassmann, G. Renal function in heart failure: A disparity between estimating function and predicting mortality risk. Eur. J. Heart Fail. 2013, 15, 763-770. [CrossRef] [PubMed]

25. Flores-Blanco, P.J.; Manzano-Fernández, S.; Pérez-Calvo, J.I.; Pastor-Pérez, F.J.; Ruiz, F.J.R.; Carrasco-Sánchez, F.J.; Morales-Rull, J.L.; Figal, D.A.P.; Galisteo-Almeda, L.; Januzzi, J.L. Cystatin C-based CKD-EPI equations and n-terminal pro-b-type natriuretic peptide for predicting outcomes in acutely decompensated heart failure. Clin. Cardiol. 2015, 38, 106-113. [CrossRef] [PubMed]

26. Manzano-Fernández, S.; Flores-Blanco, P.J.; Pérez-Calvo, J.I.; Ruiz, F.J.R.; Carrasco-Sánchez, F.J.; Morales-Rull, J.L.; GalisteoAlmeda, L.; Figal, D.A.P.; Valdes, M.; Januzzi, J.L. Comparison of risk prediction with the CKD-EPI and mdrd equations in acute decompensated heart failure. J. Card. Fail. 2013, 19, 583-591. [CrossRef]

27. Cheang, I.; Liao, S.; Yao, W.; Lu, X.; Gao, R.; Zhou, Y.; Zhang, H.; Li, X. Cystatin C-based CKD-EPI estimated glomerular filtration rate equations as a better strategy for mortality stratification in acute heart failure: A STROBE-compliant prospective observational study. Medicine 2020, 99, e22996. [CrossRef]

28. Shchekochikhin, D.; Nikiforova, T.; Shilova, A.; Nesterov, A.; Baturina, O.; Gognieva, D.; Kozlovskaya, N.; Syrkin, A.; Kopylov, P. Evaluation of discriminative capacity of two formulas of CKD-EPI to predict complications after the first episode of heart failure with preserved ejection fraction. Int. J. Nephrol. Renov. Dis. 2019, 12, 113-118. [CrossRef]

29. Zamora, E.; Lupón, J.; De Antonio, M.; Vila-Domènech, J.S.; Peñafiel, J.; Galán, A.; Urrutia, A.; Domingo, M.; Bayes-Genis, A.; Li, Y.C. Long-term prognostic value for patients with chronic heart failure of estimated glomerular filtration rate calculated with the new CKD-EPI equations containing cystatin C. Clin. Chem. 2014, 60, 481-489. [CrossRef]

30. Jang, S.Y.; Yang, D.H.; Kim, H.J.; Park, B.E.; Park, Y.J.; Kim, H.N.; Kim, N.K.; Bae, M.H.; Lee, J.H.; Park, H.S.; et al. Prognostic value of cystatin $\mathrm{C}$-derived estimated glomerular filtration rate in patients with acute heart failure. Cardiorenal Med. 2020, 10, 232-242. [CrossRef] [PubMed]

31. Ferreira, J.P.; Girerd, N.; Pellicori, P.; Duarte, K.; Girerd, S.; Pfeffer, M.A.; McMurray, J.J.; Pitt, B.; Dickstein, K.; Jacobs, L.; et al. Heart 'OMics' in AGEing (HOMAGE) initiative and the High-Risk Myocardial Infarction database initiative. Renal function estimation and Cockroft-Gault formulas for predicting cardiovascular mortality in population-based, cardiovascular risk, heart failure and post-myocardial infarction cohorts: The Heart 'Omics' in AGEing (HOMAGE) and the high-risk myocardial infarction database initiatives. BMC Med. 2016, 14, 181.

32. Scrutinio, D.; Passantino, A.; Santoro, D.; Cacciapaglia, E.; Farinola, G. Prognostic value of formulas estimating excretory renal function in the elderly with systolic heart failure. Age Ageing 2008, 38, 296-301. [CrossRef]

33. Weidmann, Z.M.; Breidthardt, T.; Twerenbold, R.; Züsli, C.; Nowak, A.; von Eckardstein, A.; Erne, P.; Rentsch, K.; de Oliveira, M.T., Jr.; Gualandro, D.; et al. Prediction of mortality using quantification of renal function in acute heart failure. Int. J. Cardiol. 2015, 201, 650-657. [CrossRef] [PubMed]

34. Massari, F.; Scicchitano, P.; Iacoviello, M.; Passantino, A.; Guida, P.; Sanasi, M.; Piscopo, A.; Romito, R.; Valle, R.; Caldarola, P.; et al. Multiparametric approach to congestion for predicting long-term survival in heart failure. J. Cardiol. 2020, 75, 47-52. [CrossRef] [PubMed]

35. Massari, F.; Scicchitano, P.; Iacoviello, M.; Valle, R.; Sanasi, M.; Piscopo, A.; Guida, P.; Mastropasqua, F.; Caldarola, P.; Ciccone, M.M. Serum biochemical determinants of peripheral congestion assessed by bioimpedance vector analysis in acute heart failure. Heart Lung 2019, 48, 395-399. [CrossRef] 
36. Massari, F.; Scicchitano, P.; Ciccone, M.M.; Caldarola, P.; Aspromonte, N.; Iacoviello, M.; Barro, S.; Pantano, I.; Valle, R. Bi-oimpedance vector analysis predicts hospital length of stay in acute heart failure. Nutrition 2019, 61, 56-60. [CrossRef]

37. Massari, F.; Iacoviello, M.; Scicchitano, P.; Mastropasqua, F.; Guida, P.; Riccioni, G.; Speziale, G.; Caldarola, P.; Ciccone, M.M.; Di Somma, S. Accuracy of bioimpedance vector analysis and brain natriuretic peptide in detection of peripheral edema in acute and chronic heart failure. Heart Lung 2016, 45, 319-326. [CrossRef] [PubMed]

38. Scicchitano, P.; Massari, F. Bioimpedance vector analysis in the evaluation of congestion in heart failure. Biomark. Med. 2020, 14, 81-85. [CrossRef] [PubMed]

39. Donadio, C.; Moriconi, D.; Berta, R.; Anselmino, M. Estimation of urinary creatinine excretion and prediction of renal function in morbidly obese patients: New tools from body composition analysis. Kidney Blood Press. Res. 2017, 42, 629-640. [CrossRef]

40. Geddes, C.C.; Woo, Y.M.; Brady, S. Glomerular filtration rate-what is the rationale and justification of normalizing GFR for body surface area? Nephrol. Dial. Transpl. 2008, 23, 4-6. [CrossRef]

41. López-Martínez, M.; Luis-Lima, S.; Morales, E.; Navarro-Díaz, M.; Negrín-Mena, N.; Folgueras, T.; Escamilla, B.; Estupiñán, S.; Delgado-Mallén, P.; Marrero-Miranda, D.; et al. The estimation of GFR and the adjustment for BSA in overweight and obesity: A dreadful combination of two errors. Int. J. Obes. 2019, 44, 1129-1140. [CrossRef] [PubMed]

42. Kittiskulnam, P.; Tiskajornsiri, K.; Katavetin, P.; Chaiwatanarat, T.; Eiam-Ong, S.; Praditpornsilpa, K. The failure of glomer-ular filtration rate estimating equations among obese population. PLoS ONE 2020, 15, e0242447. [CrossRef] [PubMed]

43. Guebre-Egziabher, F.; Brunelle, C.; Thomas, J.; Pelletier, C.C.; Normand, G.; Juillard, L.; Dubourg, L.; Lemoine, S. Estimated glomerular filtration rate bias in participants with severe obesity regardless of deindexation. Obesity 2019, 27, 2011-2017. [CrossRef] [PubMed]

44. Pafundi, P.; Garofalo, C.; Galiero, R.; Borrelli, S.; Caturano, A.; Rinaldi, L.; Provenzano, M.; Salvatore, T.; De Nicola, L.; Minutolo, R.; et al. Role of albuminuria in detecting cardio-renal risk and outcome in diabetic subjects. Diagnostics 2021, 11, 290. [CrossRef] [PubMed]

45. McDonagh, T.A.; Metra, M.; Adamo, M.; Gardner, R.S.; Baumbach, A.; Böhm, M.; Burri, H.; Butler, J.; Čelutkienè, J.; Chioncel, O.; et al. 2021 ESC Guidelines for the diagnosis and treatment of acute and chronic heart failure. Eur. Heart J. 2021. [CrossRef] 